OPEN ACCESS

Edited by:

Kathrin Ohla,

Jülich Research Centre, Germany

Reviewed by:

Masahiro Yamaguchi, Kochi Medical School, Japan Diego Restrepo,

University of Colorado Denver, United States

*Correspondence: Jee Hyun Cho jeechoi@kist.re.kr Joo-Heon Yoon jhyoon@yuhs.ac

Specialty section: This article was submitted to Perception Science, a section of the journal

Frontiers in Neuroscience

Received: 24 January 2019 Accepted: 26 April 2019

Published: 28 May 2019

Citation:

Kum J, Kim JW, Braubach O, Ha J-G, Cho H-J, Kim C-H, Han H-B, Choi JH and Yoon J-H (2019) Neural Dynamics of Olfactory Perception:

Low- and High-Frequency Modulations of Local Field Potentia Spectra in Mice Revealed by an Oddball Stimulus.

Front. Neurosci. 13:478. doi: 10.3389/fnins.2019.00478

\section{Neural Dynamics of Olfactory Perception: Low- and High-Frequency Modulations of Local Field Potential Spectra in Mice Revealed by an Oddball Stimulus}

\author{
Jeungeun Kum 1,2, Jin Won Kim³, Oliver Braubach ${ }^{1}$, Jong-Gyun Ha ${ }^{3}$, Hyung-Ju Cho ${ }^{3}$, \\ Chang-Hoon Kim ${ }^{3,4,5}$, Hio-Been Han ${ }^{1,6}$, Jee Hyun Choi ${ }^{1,2 *}$ and Joo-Heon Yoon ${ }^{3,4,5 *}$
}

\footnotetext{
'Brain Science Institute, Korea Institute of Science and Technology, Seoul, South Korea, ${ }^{2}$ Division of Bio-Medical Science \& Technology, Korea Institute of Science and Technology, University of Science and Technology, Seoul, South Korea, ${ }^{3}$ Department of Otorhinolaryngology, Yonsei University College of Medicine, Seoul, South Korea, ${ }^{4}$ The Airway Mucus Institute, Yonsei University College of Medicine, Seoul, South Korea, ${ }^{5}$ Korea Mouse Phenotyping Center (KMPC), Seoul, South Korea, ${ }^{6}$ Department of Bio and Brain Engineering, Korea Advanced Institute of Science and Technology, Daejeon, South Korea
}

Recent brain connectome studies have evidenced distinct and overlapping brain regions involved in processing olfactory perception. However, neural correlates of hypo- or anosmia in olfactory disorder patients are poorly known. Furthermore, the bottom-up and top-down processing of olfactory perception have not been well-documented, resulting in difficulty in locating the disease foci of olfactory disorder patients. The primary aim of this study is to characterize the bottom-up process of the neural dynamics across peripheral and central brain regions in anesthetized mice. We particularly focused on the neural oscillations of local field potential (LFP) in olfactory epithelium (OE), olfactory blub (OB), prefrontal cortex (PFC), and hippocampus ( $\mathrm{HC}$ ) during an olfactory oddball paradigm in urethane anesthetized mice. Odorant presentations evoked neural oscillations across slow and fast frequency bands including delta (1-4 Hz), theta (6$10 \mathrm{~Hz}$ ), beta $(15-30 \mathrm{~Hz})$, low gamma $(30-50 \mathrm{~Hz})$, and high gamma $(70-100 \mathrm{~Hz})$ in both peripheral and central nervous systems, and the increases were more prominent in the infrequently presented odorant. During $5 \mathrm{~s}$ odorant exposures, the oscillatory responses in power were persistent in $\mathrm{OE}, \mathrm{OB}$, and $\mathrm{PFC}$, whereas neural oscillations of $\mathrm{HC}$ increased only for short time at stimulus onset. These oscillatory responses in power were insignificant in both peripheral and central regions of the $\mathrm{ZnSO}_{4}$-treated anosmia model. These results suggest that olfactory stimulation induce LFP oscillations both in the peripheral and central nervous systems and suggest the possibility of linkage of LFP oscillations in the brain to the oscillations in the peripheral olfactory system.

Keywords: oddball paradigm, local field potential, neural oscillations, olfaction, attention, anterior cingulate cortex, primary olfactory cortex, anterior olfactory 


\section{INTRODUCTION}

Olfactory dysfunction is a common condition, with a reported prevalence of 4 to 24.5\% (Estrem and Renner, 1987; Murphy et al., 2002; Bramerson et al., 2004; Vennemann et al., 2008; Schubert et al., 2012). Recent epidemiological studies have shown that self-reported olfactory dysfunction is more common in men than in women (Schubert et al., 2012), tends to increase with age (Doty et al., 1984a), and is related to smoking (Frye et al., 1990). The aetiologies of olfactory dysfunction are various (Doty, 2006), but are often classified as follows: (1) conductive impairment from the blockage of nasal airflow (e.g., rhinosinusitis and polyposis) (Deems et al., 1991), which happens in most patients with hyposmia or anosmia; and (2) sensorineural impairment from damage. Sensorineural impairment can be divided into two types. The first type is peripheral olfactory dysfunction, which occurs following damage to the $\mathrm{OE}$ due to upper respiratory infections, among other causes (Deems et al., 1991; Suzuki et al., 2007). The second type is central olfactory dysfunction, which occurs as a result of neurodegenerative diseases (e.g., Parkinson's disease, dementia with Lewy bodies, frontotemporal dementia, and Alzheimer's disease) (Devanand et al., 2000; Muller et al., 2002), neurological and neuropsychiatric disorders (e.g., Kallmann syndrome (Lieblich et al., 1982), epilepsy (Eskenazi et al., 1986), and schizophrenia (Turetsky et al., 2000), or head trauma (Zusho, 1982). Recent brain connectome studies have shown that the projections from the $\mathrm{OB}$ to the central brain regions such as piriform cortex, HC, amygdala, and hypothalamic nuclei ${ }^{1}$. However, the dynamics of how the bottom-up signals of odorants propagate to the central brain regions are poorly known, limiting the diagnostic evaluation of hypo- or anosmia in olfactory disorder patients.

Objective assessments of olfactory perception are critical for the diagnosis and treatment of olfactory dysfunction. As such, numerous odor identification tests have been developed for examining olfactory disorders. Among the most commonly used tests are the University of Pennsylvania Smell Identification Test (Doty et al., 1984b), Cross-Cultural Smell Identification Test (Doty et al., 1996), European Test of Olfactory Capabilities (Thomas-Danguin et al., 2003), and Sniffin Sticks test (Hummel et al., 1997). These test batteries consist of perception threshold, odor discrimination, and identification tests, which are mainly based on an individual's subjective responses. Given their reliance upon subjective responses, these tests are often accompanied by more objective olfactometric analyses (e.g., dose-response relationship or exposure-response relationship analyses). However, the use of olfactometric analyses is limited, as such analyses can be difficult to incorporate into routine clinical evaluations. Another objective assessment is electroolfactography (EOG), which measures peripheral olfactory function at the level of olfactory receptors within the nasal cavity. Various researchers have used EOG to extensively characterize the responses in both humans and animals (Shibuya, 1964; Okano and Takagi, 1974; Scott and Scott-Johnson, 2002), but this

${ }^{1}$ https://mouse.brain-map.org electrophysiological approach can only be used to evaluate the peripheral nervous system. Therefore, other methods that can examine olfactory function in both the central and peripheral nervous systems are needed.

Olfactory deficits as a consequence of central nervous system disease have been studied with non-invasive brain mapping techniques such as functional magnetic resonance imaging, positron emission tomography, magnetoencephalography, and electroencephalography (EEG) (Hawkes et al., 1997; Boesveldt et al., 2009; Baba et al., 2012; Schriever et al., 2017; Versace et al., 2017). Functional magnetic resonance imaging and positron emission tomography are increasingly being used to elucidate the specific areas of olfactory deterioration both in healthy individuals and in those with neurological and neurodegenerative diseases (Wang et al., 2005; Hummel et al., 2010; Meles et al., 2017). Several studies have revealed that olfactory deficits are not only indicated by changes in specific olfactory areas but also by changes in the functional connectivity of the olfactory network (Kollndorfer et al., 2015; Reichert et al., 2018). Recently, the neural correlates of olfactory deficits in neurodegenerative diseases have been identified, such as absent olfactory eventrelated potentials or decreased alpha $1(8-10 \mathrm{~Hz})$ power of the olfactory responses recorded via magnetoencephalography in patients with Parkinson's disease (Boesveldt et al., 2009; Versace et al., 2017) and weaker blood oxygen level-dependent signals in the primary olfactory cortices and insular cortices of patients in the early stages of Alzheimer's disease (Wang et al., 2010). Another study was able to reliably distinguish patients with olfactory impairment from healthy individuals by using time-frequency analysis of EEG (Schriever et al., 2017). However, there is inherently spatial and temporal insensitivity in many neuroimaging studies (Gottfried and Zald, 2005), as well as other limitations such as absent or unsatisfactory responses in olfactory evoked potential studies (Hawkes, 2006) and the inability to understand whether the olfactory deficit emanates from a peripheral nervous system disorder or a neurodegenerative central nervous system disorder. To obtain a diagnostic profile of deficits in olfaction, it will be critical to characterize the neurodynamic responses to odor exposure in the olfactory regions of both the nasal cavity and the brain.

Our aim in this study was to characterize odor-evoked neural oscillation patterns via invasively recording local field potentials (LFPs) simultaneously from both the peripheral (OE) and central (OB, PFC, and $\mathrm{HC}$ ) nervous systems using a passive oddball paradigm. The brain areas of interest were chosen based on their relevance to olfactory consciousness or processing, as well as their detectability in human EEG. For example, beta and gamma oscillations in the PFC are known to reflect olfactory consciousness (Mori et al., 2013) and theta oscillations in the HC are known to be driven by olfactory input (Kay et al., 2009). In our study, we presented two different odorants under the oddball paradigm and characterized the olfactory evoked oscillations for both repetitive and rare stimuli in multiple sites of brains. In order to exclude the neuromodulation of olfaction via topdown regulation, we applied urethane anesthesia and delivered a precise amount of odorant via computerized olfactometer. 
A time-frequency analysis of slow and fast neural oscillations was conducted to identify the possible occurrence of long-term habituation on control mice and to compare the responses with the ones obtained from anosmia mouse model with epithelial injury.

\section{MATERIALS AND METHODS}

\section{Animals}

All surgical and experimental procedures were followed by Korean Animal and Plant Quarantine Agency Publication No. 12512, partial amendment 2014, conforming to NIH guidelines (NIH Publication No. 86-23, revised 1985). All the procedures were approved by the Institutional Animal Care and Use Committee of the Korean Institute of Science and Technology (AP-2014L7002). Ten mice (C57BL/6N, 8-12 weeks old, body weight: $22-28 \mathrm{~g}$ ) were used in this study. The animals were housed in a colony maintained on a 12-hour light/dark cycle at $22^{\circ} \mathrm{C}$ with $55 \%$ humidity and allowed ad libitum access to food and water. The animals were born and raised in this specific pathogen-free environment.

\section{Surgery and LFP Recordings}

To implant the electrode for the LFP recordings, we first anesthetized the mice by administering urethane $(1.5 \mathrm{~g} / \mathrm{kg})$ intraperitoneally, and then placed and fixed the mice in a stereotaxic apparatus (Model 902; David Kopf Instruments, Tujunga, CA, United States). All LFP recordings were performed with sterile bipolar Teflon-coated tungsten electrodes (Model No. 796000, A-M Systems, Sequim, WA, United States). The electrode impedance was $100-300 \mathrm{k} \Omega$ when measured with an impedance tester (test frequency at $1 \mathrm{kHz}$, nanoZ, Plexon, Inc., Dallas, TX, United States). To record OE, the electrode was placed in or near the left or right olfactory mucosa (just rostral to the nasofrontal suture, $7.0 \mathrm{~mm}$ anterior and $0.3 \mathrm{~mm}$ lateral to the bregma point, $0.5 \mathrm{~mm}$ below the skull surface). In the brain, three electrodes were implanted in OB (anteroposterior: $4.8 \mathrm{~mm}$, mediolateral: $1.2 \mathrm{~mm}$, dorsoventral: $-1.1 \mathrm{~mm}$ from bregma), PFC (anteroposterior: $0.5 \mathrm{~mm}$, mediolateral: $1.54 \mathrm{~mm}$, dorsoventral: $-2.7 \mathrm{~mm}$ from bregma), and HC (anteroposterior: $-2.0 \mathrm{~mm}$, mediolateral: $1.5 \mathrm{~mm}$, dorsoventral: $-1.4 \mathrm{~mm}$ from bregma). For the ground electrode, a sterilized micro screw was implanted on the interparietal bone. All stereotaxic coordinates of the electrodes were in accordance with the mouse brain (Paxinos et al., 2001).

After the surgery, we calibrated the density of odorant and ensured a quick and complete vacuuming of odorant with a photo-iodine detector (miniPID 200B; Aurora scientific, Aurora, ON, Canada). Then the mice were moved to a custommade mouse restrainer with their heads fixed in front of the olfactometer. The nose tip of the animal was placed in front of the olfactometer outlet with a $1-\mathrm{cm}$ gap. We recorded LFPs during the oddball task with a Cerebus amplifier (Blackrock Microsystems, Salt Lake City, UT, United States). All signals were digitized with a $2-\mathrm{kHz}$ sampling rate and bandpass filtered from 0.3 to $500 \mathrm{~Hz}$.

\section{Odor Oddball Paradigm}

The olfactometer was designed to provide a constant flow of air at the tube outlet and quick vacuuming of odors (Figure 1A). Each odor was diluted from a saturated vapor with filtered air and vaporized by pumped air via an air pump (Active Aqua Air Pump (two outlets, 3 W); Hydrofarm, Inc., Petaluma, CA, United States). The streaming of odors was blocked or opened by a solenoid valve (HTV 0301-3; KCCPR, Seoul, South Korea), which was controlled by custom-built MATLAB software (The MathWorks, Inc., Natick, MA, United States). When the solenoid valve was open, the odor was constantly injected into the animal's naris, whereas when the solenoid valve was closed, the air was naturally emitted from the ventilator. For constant airflow, the nose piece was designed to have two layers, an outer layer for constant delivery of filtered air and an inner layer for the delivery of odors. Within the inner layer, two tubes were aligned to deliver the odors. To avoid cross-contamination, a tube was connected from the inner layer to a vacuum pump (Vario 18; Medela, Baar, Switzerland), which was coupled to the solenoid valve and opened to remove the odors.

For the olfactory oddball paradigm, methyl salicylate (>99\% purity, mineral oil solution, ratio of odor to solvent was 3:1; Sigma Aldrich, Inc., St. Louis, MO, United States) and ethyl acetate (>99.5\% purity, distilled water solution, odor to solvent ratio was 1:1 Sigma Aldrich, Inc., St. Louis, MO, United States) were used at $10 \%$ of saturated vapor for all odor experiments. The rising and falling times of the olfactometer were approximately 100 and $130 \mathrm{~ms}$, respectively, with no statistical difference between the two odors (Welch's $t$-test, $p>0.05$ ). For odor delivery, a constant flow of filtered air $(1 \mathrm{~L} / \mathrm{min})$ was delivered through the outer layer of the nose piece, while odor stimuli were diluted by pumped air $(200 \mathrm{~mL} / \mathrm{min})$. The solenoid valve connected to the vacuum pump was opened at the end of the stimulation (1.5 L/min) to directly remove odor stimuli. In this study, we used methyl salicylate and ethyl acetate as odorants. To avoid the odorant-type effect, we applied methyl salicylate and ethyl acetate as standard and deviant stimuli, respectively, to half of the mice ( 3 control and $2 \mathrm{ZnSO}_{4}$-treated mice) and applied ethyl acetate and methyl salicylate as standard and deviant stimuli, respectively, to the other half of the mice (2 control and $3 \mathrm{ZnSO}_{4}$-treated mice). The standard and deviant odors were randomly shuffled with a 5:1 ratio, as depicted in Figure 1B. The stimulation period was $5 \mathrm{~s}$ and the inter-stimulus interval was $20 \mathrm{~s}$. The rising and falling phases were measured by a photo-iodine detector (miniPID 200B; Aurora scientific, Aurora, ON, Canada). A session was composed of 84 stimuli (70 standard stimuli and 14 deviant stimuli) lasting $35 \mathrm{~min}$. For each mouse, we performed three or four experimental sessions, with an inter-session interval of $>30 \mathrm{~min}$. After the experiment, the animals were sacrificed for histological confirmation of the electrode tip positions.

\section{Data Analysis}

All LFP signals were normalized by the average power of the signals by MATLAB software (The MathWorks, Inc., Natick, MA, United States) in the $150-200 \mathrm{~Hz}$ frequency range from 


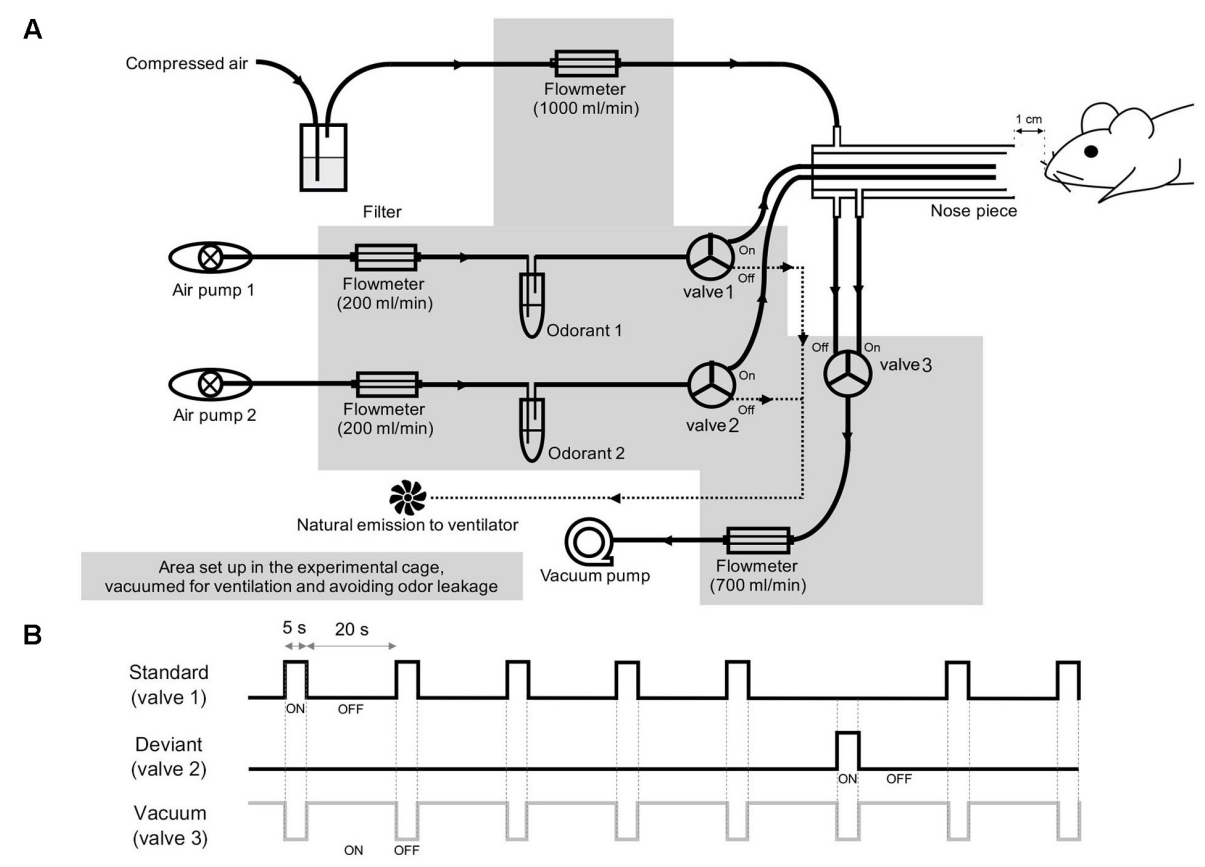

FIGURE 1 | Experimental setup. (A) Schematic diagrams of the olfactometer that was used to deliver the two odor stimuli. (B) Schematic overview of the two-odor oddball paradigm. The standard, deviant, and vacuum channels were paired with separate solenoid valves, which are numbered in (A).

the 5-min baseline period to match the interface impedance for all electrodes.

For the single-trial LFP display, a Butterworth filter was used for all bands of interest including the delta $(\delta, 1-4 \mathrm{~Hz})$, theta $(\theta$, $6-10 \mathrm{~Hz})$, beta $(\beta, 15-30 \mathrm{~Hz})$, low gamma (low $\gamma, 30-50 \mathrm{~Hz})$, and high gamma (high $\gamma, 70-100 \mathrm{~Hz}$ ) bands. For the $z$-score power analysis, a short-time Fourier transform was used to evaluate the change in the normalized power in 1-s time windows at a time resolution of $100 \mathrm{~ms}$ and frequency resolution of $0.5 \mathrm{~Hz}$ $\left[z\right.$-score $\left.=\left(P_{\text {stim }}-P_{\text {base }}\right) / P_{\text {base }}\right]$. An epoch was extracted for every stimulus from $5 \mathrm{~s}$ before the onset to $15 \mathrm{~s}$ after the offset, and the epochs contaminated by noise were excluded. Deviant stimulation trials and standard stimulation trials before the deviant trials were used in the difference analysis. For the power spectra of LFPs, the baseline and stimulus period powers of the standard stimulation were divided by the total power of the baseline data ( $5 \mathrm{~s}$ ) for each frequency. To measure withintrial decreases in oscillatory power, six control mice standard trials were aligned by trial order and the $z$-score power of each trial was averaged. In this study, we performed a Chi-square test for normality and then applied Welch's $t$-tests for normally distributed data and non-parametric Wilcoxon rank-sum tests for non-normally distributed data.

\section{Anosmia Model With $\mathrm{ZnSO}_{4}$-Treated OE Injury}

Bilateral intranasal perfusion with $20 \mu \mathrm{L}$ of $10 \% \mathrm{ZnSO}_{4}$ was accomplished to destroy olfactory sensory neurons with a 0.3 $\mathrm{M}$ chloral hydrate solution (5 $\mathrm{mg} / \mathrm{g}$ body weight) for four mice. The $\mathrm{ZnSO}_{4}$ treatment is known to destroy the mature olfactory neuroreceptors without affecting progenitor cells, thus allowing subsequent neurogenesis processes to occur (Cancalon, 1982). The destruction of the OE was confirmed histologically using hematoxylin and eosin staining and anti-olfactory marker protein (anti-OMP antibody, Osenses Pty Ltd., Keswick, Australia) immunostaining after the experiments. The detailed procedures and treatment effects are described in our previous study (Cho et al., 2018). Six mice that received bilateral intranasal perfusion with $20 \mu \mathrm{L}$ of a $0.3-\mathrm{M}$ chloral hydrate solution served as the control group.

\section{RESULTS}

\section{Olfactory Responses in Control Mice}

Baseline $\mathrm{OE}$ and $\mathrm{OB}$ activity consisted of high-amplitude, regularly fluctuating slow oscillations (1-4 Hz) and lowamplitude, irregular fast waves. In response to odor release, rhythmical changes were observed in a prominent way in all recorded areas (Figures 2A,B and Supplementary Figure S1). In the $\mathrm{OE}$, clear $\delta$ oscillations were elicited at odor exposure and were accompanied by fast responses. Fast rhythms occurred during odor exposure (Figure 2B).

We next investigated whether any desensitization patterns appeared over the exposure time and across the trials by plotting the time traces of the oscillatory powers across the trials (Figure 3). In order to ensure that all parameters were comparable, we calculated the $z$-scores by subtracting the baseline power from the power of each frequency band and then dividing it by the baseline power. In the OB, PFC, and 


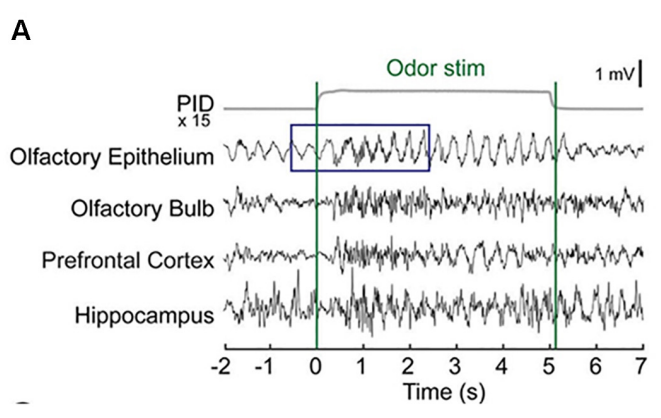

B

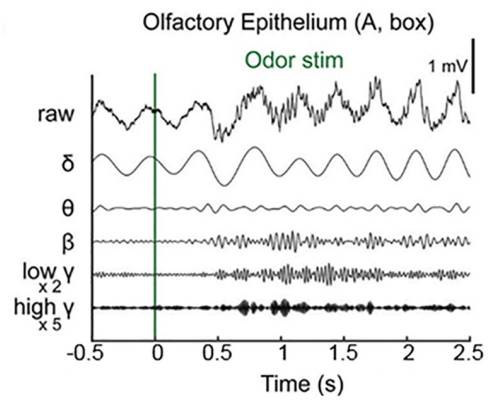

FIGURE 2 | Simultaneous recording of local field potentials (LFPS) during odor stimulation. (A) Example of stimulus-locked LFPs and the odorant concentration. Single-trial LFPs are displayed after being bandpass filtered with a cut-off frequency from 1 to $100 \mathrm{~Hz}$. Averaged photo ionization detector (PID) signals averaged over 70 trials (one session) are depicted for the odorant concentration. The vertical lines indicate the onset and offset moments of odor release. Methyl salicylate was released in this trial. The rising time of the tested odorants in this experiment was $\sim 100 \mathrm{~ms}$. (B) Examples of the frequency components of the LFPs in the early responses ( $2.5 \mathrm{~s})$ of the olfactory epithelium. Specifically, the $\delta(1-4 \mathrm{~Hz}), \theta(6-10 \mathrm{~Hz}), \beta(15-30 \mathrm{~Hz})$, low $\gamma(30-50 \mathrm{~Hz})$, and high $\gamma(70-100 \mathrm{~Hz})$ bands.

HC, fast rhythms were more eminent than were slow rhythms. The LFP power spectral density was increased by odor release across the frequency bands included in the $\delta, \theta, \beta$, low $\gamma$, and high $\gamma$ bands. Generally, the power shows that the initial strong responses were attenuated over time but the patterns were different among the regions. The temporal profiles of powers show that the elevated powers persisted in $\mathrm{OE}, \mathrm{OB}$, and PFC during the stimulation period, while the change ceased early in HC (Supplementary Figure S2).

To investigate the trial effect, we performed a linear regression analysis of power across the trials. We performed the analysis for early (0-2 s) and late (3-5 s) periods, separately, to observe when the repetition of trials has an influence. Generally, the influences of trial repetition were similar for the early vs. late periods: $\delta$ power of $\mathrm{OE}, \theta$ power of $\mathrm{OE}$ and $\mathrm{OB}$, low $\gamma$ power of PFC decreased significantly as trial repeated $(p<0.05$, onesided $t$-test). On the other hand, $\beta$ powers in OE and PFC, and high $\gamma$ power of PFC decreased significantly only during early period and $\delta$ power of PFC decreased significantly only during late period ( $p<0.05$, one-sided $t$-test) as the trial was repeated. All results of linear regression and test of non-zero slope were depicted in Supplementary Figure S3.

We observed distinctive response patterns for different frequencies by comparing the power values during stimulation to baseline powers. The significantly changed time periods were presented in the bar graphs under the spectrograms (Figure 4). For the $\delta$ power, the OE showed the most dramatically increased response compared to baseline during all trials, while the $\delta$ power of the other examined regions were weaker than that in the OE. High $\gamma$ was increased when compared to baseline in all regions. The $\theta$ power of the stimulation period was reduced in the three central nervous system regions during repeated trials, while the $\theta$ power in the OE remained high during repeated trials. The HC showed brief changes at the odor onset in all trials.

\section{Responses to Deviant Odors During the Oddball Paradigm}

A time-frequency analysis was conducted on the spectrogram of each LFP using a frequency bin width of $0.5 \mathrm{~Hz}$ and a temporal bin width of $1 \mathrm{~s}$ with a moving window of $100 \mathrm{~ms}$. We first obtained the averaged spectrograms of the baseline-adjusted $z$-score for two different types of stimulation (methyl salicylate as the standard odor stimulus and ethyl acetate as the deviant odor stimulus or vice versa), as presented in Supplementary Figures S4, S5. We also calculated the differential spectrograms by averaging the differential spectrograms for the deviant stimulus compared to the previous standard stimulus. Given that the power decreases as the frequency increases with the power law, we used the $z$-scores (ratio of the stimulus power subtracted by stimulus power to baseline power) to draw the spectrograms.

To merge the spectrograms from two different stimulation conditions, we fitted the $z$-score distribution of each data point from a 500-ms window timescale with a lognormal distribution and collected the $\mu$ value, an average of the logarithmic power in the 500-ms window (Figure 4). A rapid response was observed after odor stimulation. To identify the significant differences in the responses and frequencies compared to baseline (Figures $\mathbf{4 A , B}$ and Supplementary Figures S4-S6) or between the standard and deviant stimuli (Figures 4C,D and Supplementary Figures S4-S6), we performed a Wilcoxon rank-sum test with a significance level of 0.05 . The bar graphs under the spectrograms indicate the significant responses at each rhythm. We observed two types of responses: (i) persistent responses, where the significant increase of oscillatory power was maintained throughout odor exposure and (ii) transient responses, where the oscillatory power significantly increased briefly only at stimulus onset.

In the $\mathrm{OE}, \mathrm{OB}$, and $\mathrm{PFC}$, significant responses appeared at $\sim 100 \mathrm{~ms}$ after odor stimulation for both the standard and deviant stimuli. The power of these rapid responses was significantly stronger for the deviant stimuli than for the standard stimuli in all examined regions, indicating that the mice responded to the oddball stimulation paradigm. On the other hand, this response appeared later in the $\mathrm{HC}$ than it did in the other measured regions, with an approximate delay of 100-200 ms. Additionally, in the HC, the significant responses were short-lived for all frequency bands. 
A

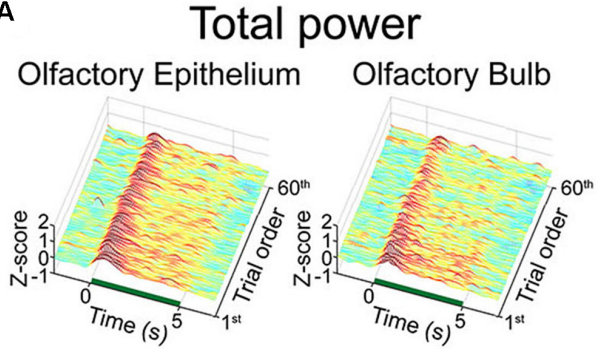

Prefrontal Cortex

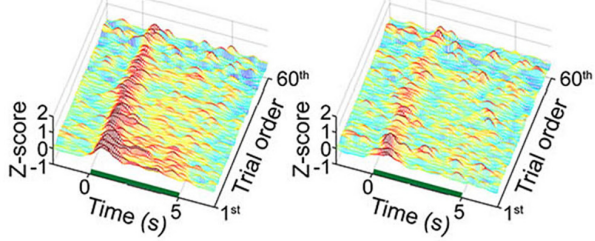

C

$\theta$ power

Olfactory Epithelium Olfactory Bulb

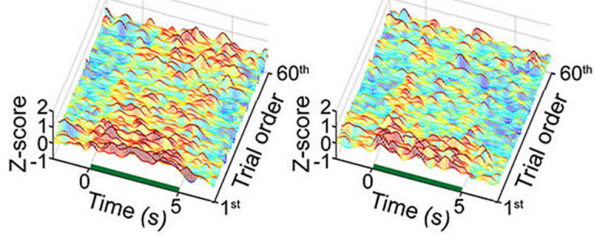

Prefrontal Cortex

Hippocampus

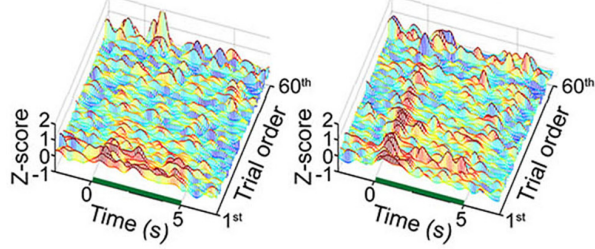

E Olfactory Epithelium Olfactory Bulb

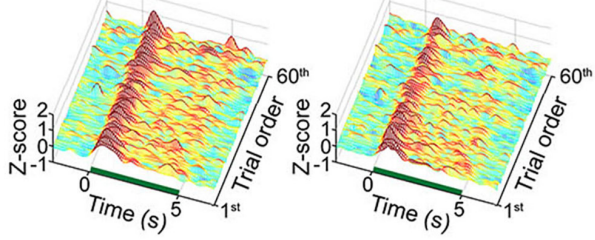

Prefrontal Cortex

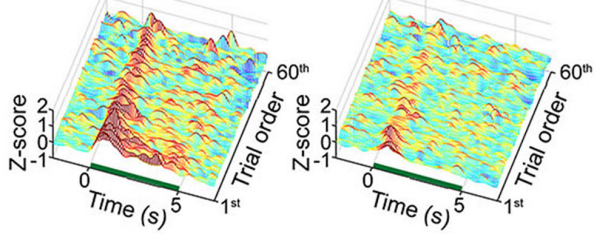

B $\delta$ power

Olfactory Epithelium Olfactory Bulb

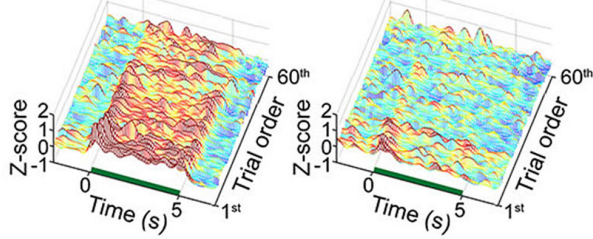

Prefrontal Cortex Hippocampus

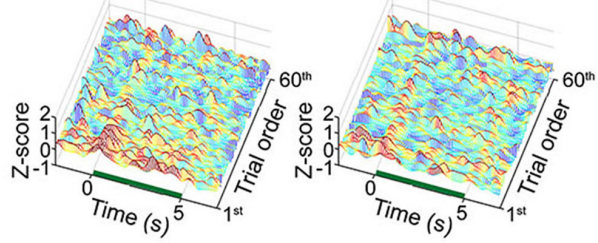

D $\quad \beta$ power

Olfactory Epithelium Olfactory Bulb

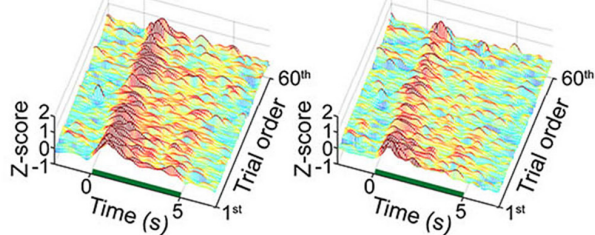

Prefrontal Cortex Hippocampus

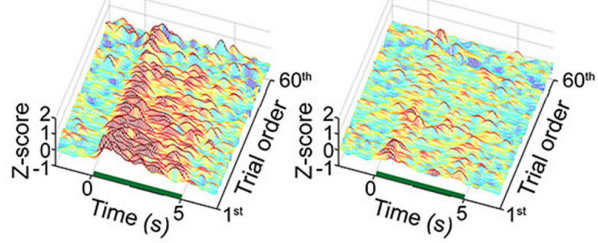

F $\quad$ high $y$ power

Olfactory Epithelium Olfactory Bulb

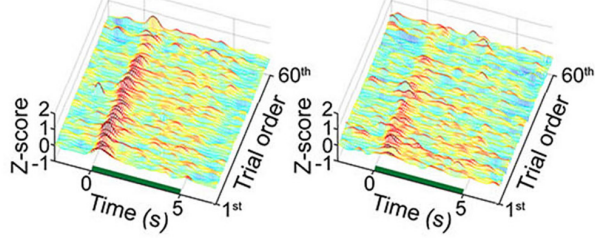

Prefrontal Cortex

Hippocampus

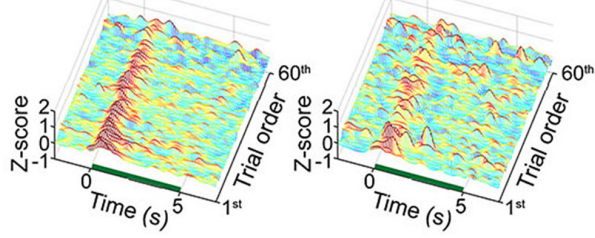

FIGURE 3 | Desensitization patterns of the local field potential (LFP) signals at each channel. The mean z-scores of each trial of the standard stimulation condition are aligned by trial number. The $x$-axis indicates the time course of each trial from the 2-second baseline period to the post-stimulation period. The $y$-axis indicates the first 60 standard trials during each session. (A) Mean z-score of the total power (1-100 Hz). (B) Mean z-score of $\delta$ (1-4 Hz). (C) Mean z-score of $\theta$ (6-10 Hz). (D) Mean z-score of $\beta$ (15-30 Hz). (E) Mean z-score of low $\gamma(30-50 \mathrm{~Hz})$. (F) Mean $z$-score of high $\gamma(70-100 \mathrm{~Hz})$. 
A

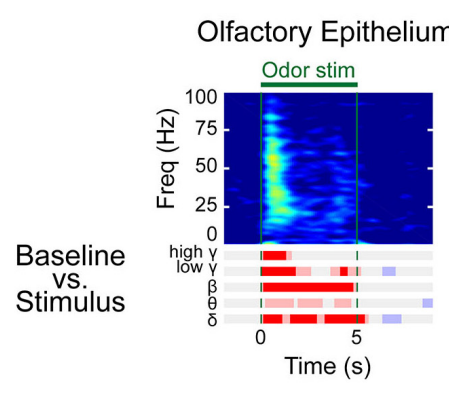

B

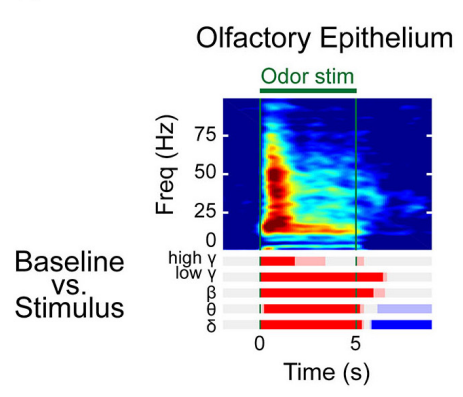

\section{Standard}
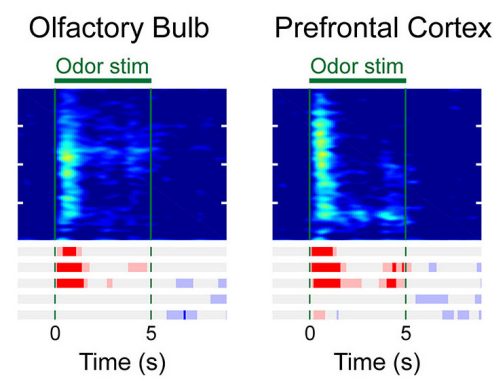

Hippocampus

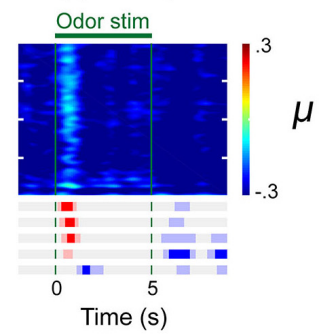

Deviant

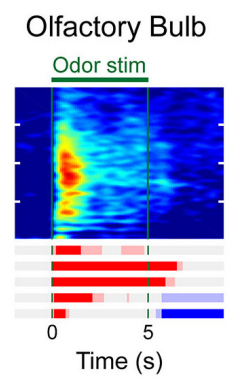

Prefrontal Cortex

\section{Hippocampus}
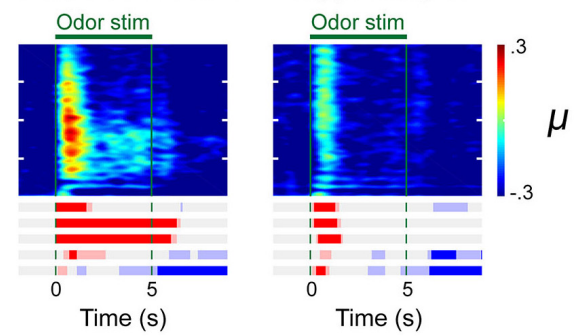

Deviant - Standard

C
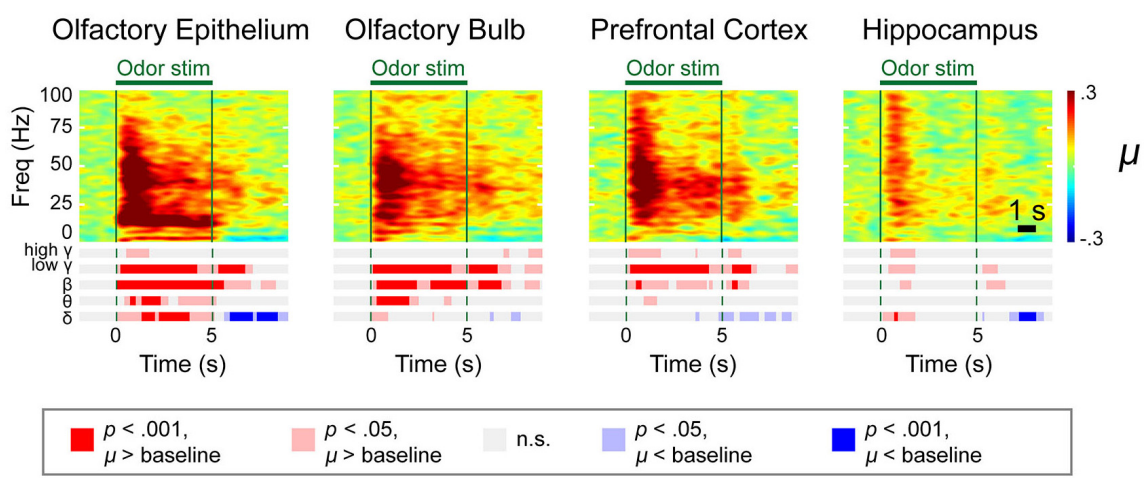

$p<.05$
$\mu>$ baseline

n.s.

$p<.05$
$\mu<$ baseline

$p<.001$

$\mu<$ baseline

FIGURE 4 | Spectrograms of the $\mu$ values of the lognormal fit of the $z$-score power from two different stimulation conditions in control mice. Methyl salicylate was used for the standard stimulation condition and ethyl acetate was used for the deviant stimulation condition or vice versa. The bars underneath the spectrograms indicate the statistical significance at each frequency band (Wilcoxon rank-sum tests). The red or blue bar indicates $p<0.001$ and pink or sky blue bars indicate $0.001 \leq p<0.05 . \delta(1-4 \mathrm{~Hz}), \theta(6-10 \mathrm{~Hz}), \beta(15-30 \mathrm{~Hz})$, low $\gamma(30-50 \mathrm{~Hz})$, and high $\gamma(70-100 \mathrm{~Hz})$. (A) Standard trial $\mu$ value spectrogram. (B) Deviant trial $\mu$ value spectrogram. (C) Deviant - standard trial $\mu$ value differential spectrogram.

The response patterns to the standard and deviant stimuli were different in all channels. For example, persistently elevated responses of $\beta$ and low $\gamma$ bands were observed with respect to the deviant stimuli but not with respect to the standard stimuli. In the case of the OE, the persistent responses of all oscillations were observed but the significance was stronger for the deviant stimuli compared to the standard stimuli.

While persistent responses of some frequency bands were observed in $\mathrm{OE}, \mathrm{OB}$, and $\mathrm{PFC}$, all responses in the $\mathrm{HC}$ were transient for all frequency bands. When we compared the HC responses during standard versus deviant stimuli, $\theta$ power did not show any statistically significantly different power in HC. Also, in HC, the undershooting of power was more eminent particularly in $\delta$ and $\theta$ frequencies with respect to deviant stimuli. For standard stimuli, reduction of the $\delta$ and $\theta$ oscillations were observed after the cessation of odor stimulation in the $\mathrm{OE}$ and $\mathrm{OB}$ and during the late period of odor stimulation in the PFC and HC (Figure 4A). For deviant stimuli, steady and longer desynchronization of the $\delta$ and $\theta$ oscillations were observed in each area after the cessation of odor stimulation or during the late period of stimulation (Figure 4B). The differential spectrogram revealed that the desynchronization of the $\delta$ oscillations was greater for the deviant than for the standard stimulation condition (Figure 4C). Averaged spectrograms of the two different conditions are shown in Supplementary 
Figures S4, S5. Both conditions showed immediate responses after odor stimulation, while late-period responses showed different patterns.

The differential spectrogram (Figure 4C) revealed that the power of the $\delta$ to high $\gamma$ rhythms increased in the OE during stimulation. As the pink and red bar indicates the significance, in the $\mathrm{OB}$, the power of the $\delta$ to low $\gamma$ rhythms increased during the stimulation period compared to baseline. In the PFC, the $\beta$ to high $\gamma$ power increased during odor stimulation compared to baseline. The $\beta$ and low $\gamma$ in the OE, OB, and PFC showed persistent responses. Unlike the other central nervous system regions, the $\mathrm{HC}$ demonstrated transient responses to deviant stimuli in all oscillatory powers.

\section{Significantly Reduced Oscillations in $\mathrm{ZnSO}_{4}$-Treated Mice}

The odor evoked LFPs were investigated in a peripheral anosmia model. We produced peripheral anosmia by injecting $\mathrm{ZnSO}_{4}$ directly into both sides of the OE. The hematoxylin and eosin stained and anti-olfactory marker protein immunostained images revealed disruption of the epithelial tissue as well as the absence of mature olfactory response neurons (Figure 5).
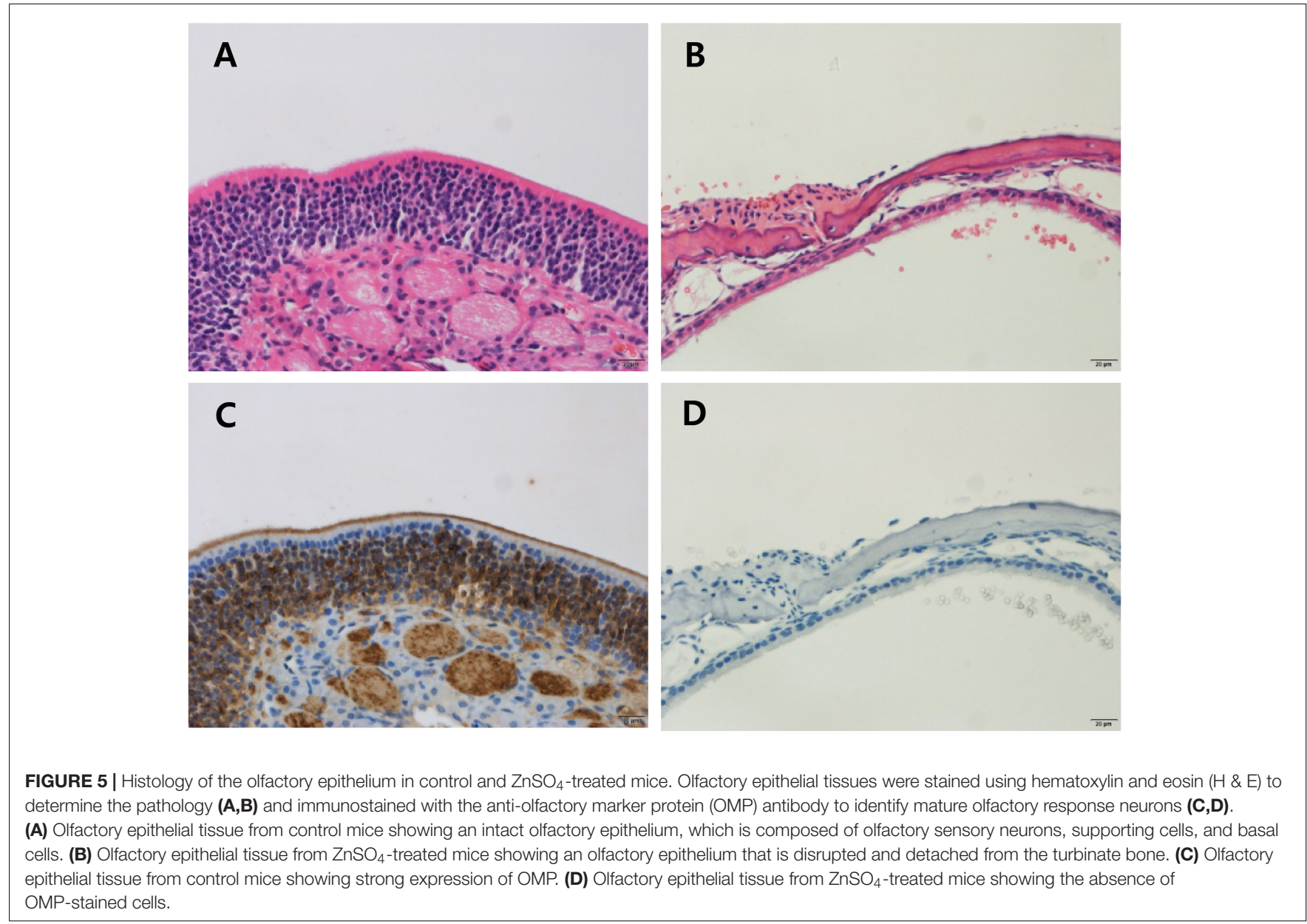

We first analyzed the pre-stimulus power to investigate whether the damage of $\mathrm{OE}$ has altered the baseline rhythmical fluctuations of $\mathrm{OE}$ and brain regions. We have found that not only $\mathrm{OE}$ but also OB, PFC, and HC presented altered baseline powers (Supplementary Figure S7). Briefly, $\delta$ power significantly decreased in OE and $\mathrm{OB}$ of $\mathrm{ZnSO}_{4}$-treated mice compared to the control mice. On the other hand, $\theta$ power significantly increased in all recorded area of $\mathrm{ZnSO}_{4}$-treated mice. Significant increase of $\beta$ power was observed in $\mathrm{OE}, \mathrm{OB}$, and $\mathrm{HC}$ in $\mathrm{ZnSO}_{4}$-treated mice.

In order to investigate the evoked responses, we performed the spectral analysis with respect to standard and deviant odorants. Compared to control mice, which showed an immediate increase in power in all frequency bands, the LFPs of $\mathrm{ZnSO}_{4}$-treated mice did not show any prominent differences during odor exposure compared to baseline (Figures 6A,B). In the OE, the amplitudes of filtered oscillations from $\delta$ to high $\gamma$ were the same before and after odor exposure (Figure 6B), which contrasted with the filtered time traces of control mice.

Our time-frequency analysis revealed impaired olfactory responses in all recorded regions of $\mathrm{ZnSO}_{4}$-treated mice and a lack of significant responses in all regions during exposure to standard stimuli, although transient responses 
A

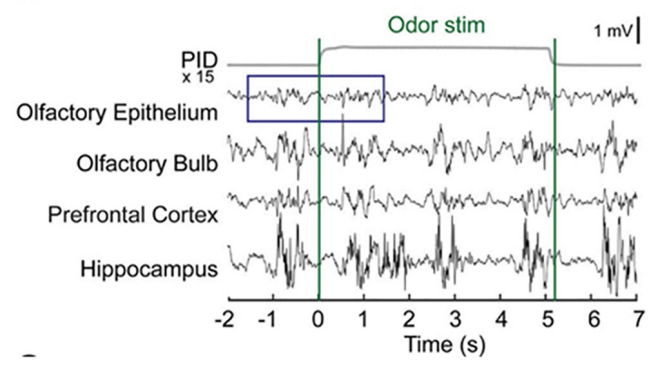

B

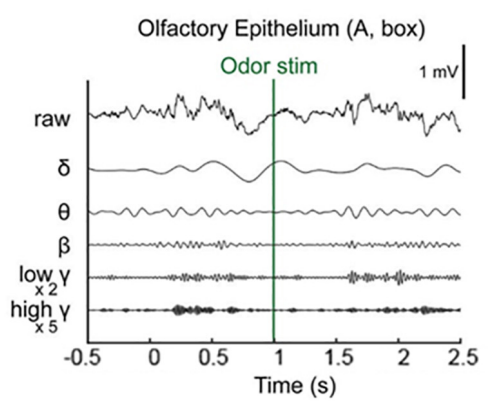

FIGURE 6 | Stimulus-locked local field potentials (LFPS) in $\mathrm{ZnSO}_{4}$-treated mice. (A) Examples of stimulus-locked LFPs from ZnSO differences from before to after odor stimulation in the raw time traces of single-trial LFPs. Averaged photo ionization detector (PID) signals averaged over 70 trials (one session) are depicted for the odorant concentration. The vertical lines indicate the onset and offset moments of odor release. Methyl salicylate was released in this trial. The rising time of the tested odorants in this experiment was $\sim 100 \mathrm{~ms}$. (B) Examples of the frequency components of the LFPs from before stimulation to the early responses $(-1.5 \sim 1.5 \mathrm{~s})$ in the olfactory epithelium. Specifically, the $\delta(1-4 \mathrm{~Hz}), \theta(6-10 \mathrm{~Hz}), \beta(15-30 \mathrm{~Hz})$, low $\gamma(30-50 \mathrm{~Hz})$, and high $\gamma(70-100 \mathrm{~Hz})$ bands.

were observed in the $\mathrm{OB}$ and $\mathrm{PFC}$ during exposure to deviant stimuli (Figure 7). In the OE, no statistical differences were observed for any of the frequencies from $\theta$ to high $\gamma$ compared to baseline in the $\mathrm{ZnSO}_{4}$-treated mice. In the $\mathrm{OB}$, the low $\beta$ response of $\mathrm{ZnSO}_{4}$-treated mice was reduced compared to that of control mice. In the PFC and $\mathrm{HC}$, statistical differences in the $\theta$ to high $\gamma$ frequencies between the baseline and stimulation periods were reduced in $\mathrm{ZnSO}_{4}$-treated mice when compared to the differences in control mice.

The averaged power spectrogram of the two groups, in which different standard and deviant stimuli were used on $\mathrm{ZnSO}_{4}$ treated mice, as previously described, showed transient responses for both the standard and deviant conditions in the $\mathrm{OE}, \mathrm{OB}$, and PFC, but the response patterns were slightly different (Supplementary Figures S8-S10).

\section{DISCUSSION}

In this study, we simultaneously measured LFPs from the main $\mathrm{OE}$, a peripheral area that contains olfactory sensory neurons, the $\mathrm{OB}$, the direct receiver of signals from olfactory sensory neurons, and other higher-order regions, including the PFC and $\mathrm{HC}$, using an olfactory oddball paradigm in both healthy control and $\mathrm{ZnSO}_{4}$-treated anosmic mice. With this measurement, we observed the absence of odor responses in $\mathrm{ZnSO}_{4}$-treated mice compared to healthy control in both peripheral and central regions.

Concerning the emergence of peripheral nervous system neural oscillations along with central nervous system oscillations during odor stimulation, our results showed that OE oscillations from $\delta$ to high $\gamma$ emerged during odor stimulation. These findings are in line with previous studies, including one study that simultaneously observed high frequency oscillations at the olfactory mucosa and gamma waves in the rat piriform cortex (Vanderwolf, 2000), as well as EOG studies that observed $10-60 \mathrm{~Hz}$ oscillations in various vertebrates, from fish, amphibians, and reptiles to mammals (Hamilton and Kauer, 1989; Suzuki et al., 2004; Lapid and Hummel, 2013; Mori et al., 2013). The persistent responses of the OE are consistent with a previous in vivo catfish study that identified olfactory organ oscillations referred to peripheral waves (Parker et al., 2000). While many of these studies focused on specific oscillatory bands, we observed that $\delta$ to high $\gamma$ rhythms emerged simultaneously during odor stimulation in the OE.

Slow oscillations with a frequency lower than $5 \mathrm{~Hz}$ have been known to be reported in multiple brain regions, including $\mathrm{OB}$, primary olfactory cortices, frontal cortex, and HC during sleep and anesthetic states (Kay et al., 2009; Ito et al., 2014; Yanovsky et al., 2014; Chi et al., 2016). These rhythms are called slow oscillations (Yanovsky et al., 2014) or respiratory rhythms (Kocsis et al., 2018). Recently, there were discussions on whether respiration-related slow oscillations reflect internal processing or are simply entrained by respiratory inputs (Lockmann et al., 2016). Observations with increased coherence of PFC and $\mathrm{HC}$ oscillations on 2-5 Hz during thalamic nucleus reticularis $(\mathrm{nRE})$ stimulation indicate that respiratory rhythm could be influenced by internal processing (Kocsis et al., 2018). On the other hand, HC slow rhythms, which is coherent with respiratory-related oscillations, could be generated independently from hippocampal theta oscillations (Chi et al., 2016; Lockmann et al., 2016).

Fast oscillations have been reported in both awake and anesthetized mice. For example, $\beta$ oscillations have been observed during exploration or odorant discrimination or memory tests (Kay et al., 2009; Kay, 2014; Fourcaud-Trocme et al., 2014) as well as under urethane anesthesia with olfactory stimulation (Neville and Haberly, 2003; Fourcaud-Trocme et al., 2014). For the generation of $\beta$ oscillations, olfactory cortices, such as pyriform cortex are suggested as taking roles for influencing and cooperating with OB (Kay et al., 2009; Martin and Ravel, 2014). Likewise, $\gamma$ oscillations are also observed on urethane anesthetized rat during odor stimulation (Neville and Haberly, 2003; Fourcaud-Trocme et al., 2014). Compared to $\beta$ oscillations, odor-evoked $\gamma$ oscillations are known as local oscillations of OB (Kay et al., 2009), with multiple studies 
A

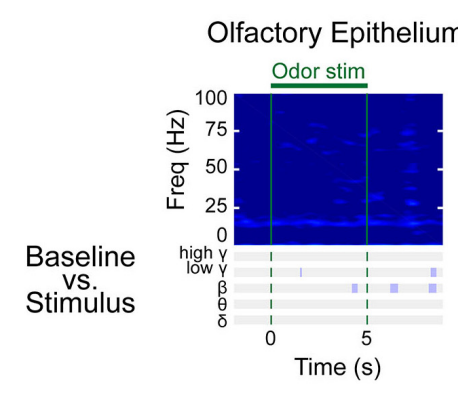

B

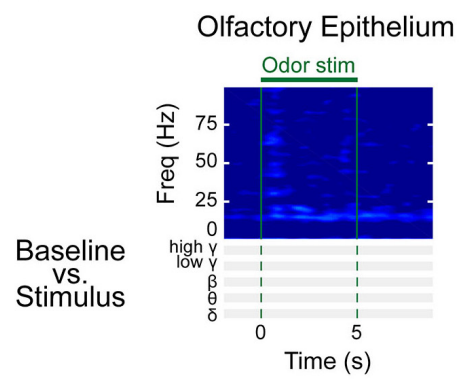

C

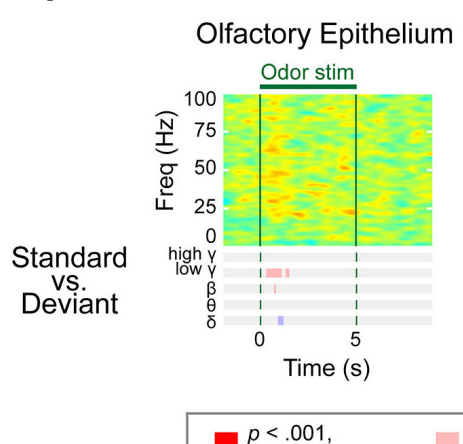

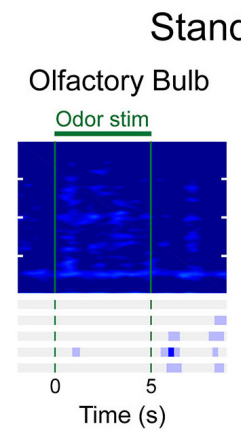

Standard

\section{Deviant}

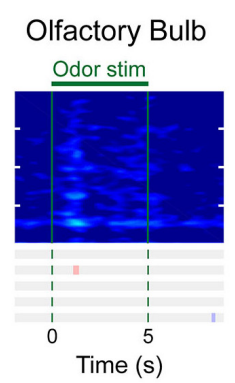

Prefrontal Cortex

\section{Hippocampus}
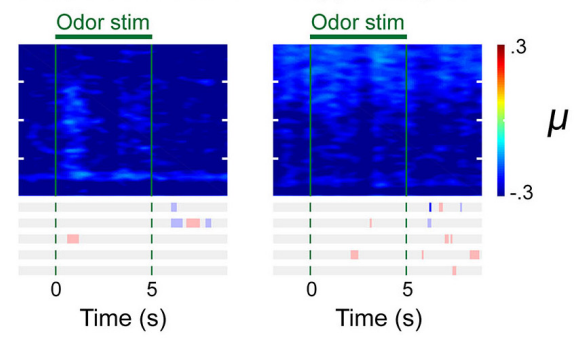

Deviant - Standard

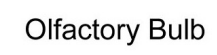

Prefrontal Cortex

Hippocampus
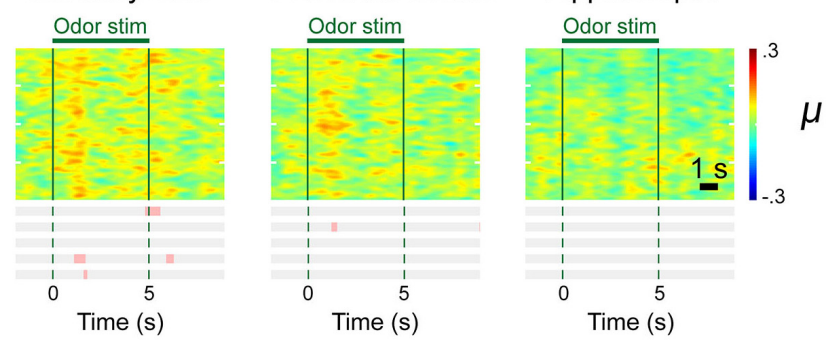

$p<.001$

$\mu<$ baseline

FIGURE 7 | Spectrograms of the $\mu$ values of the lognormal fit of the $z$-score power from two different stimulation conditions in $\mathrm{ZnSO}_{4}$-treated mice. Methyl salicylate was used for the standard stimulation condition and ethyl acetate was used for the deviant stimulation condition or vice versa. The bars underneath the spectrograms indicate the statistical significance at each frequency band (Wilcoxon rank-sum tests). The red or blue bar indicates $p<0.001$ and pink or sky blue bars indicate $0.001 \leq p<0.05 . \delta(1-4 \mathrm{~Hz}), \theta(6-10 \mathrm{~Hz}), \beta(15-30 \mathrm{~Hz})$, low $\gamma(30-50 \mathrm{~Hz})$, and high $\gamma(70-100 \mathrm{~Hz})$. (A) Standard trial $\mu$ value spectrogram. (B) Deviant trial $\mu$ value spectrogram. (C) Deviant - standard trial $\mu$ value differential spectrogram.

indicating that the synaptic connection of $\mathrm{OB}$ mitral cell and granule cell underlies the generation of $\mathrm{OB} \gamma$ oscillation (Lepousez et al., 2010; Mori et al., 2013; Fukunaga et al., 2014). $\gamma$ oscillations are delivered with the respiratory cycle and are involved in fine discrimination of odor (Beshel et al., 2007; Kay et al., 2009; Kay, 2014).

The present study also showed that these oscillations emerge from both peripheral and central nervous system regions simultaneously during odor perception. Dorries and Kauer (2000) speculated that the in vivo olfactory epithelial oscillations that they observed in the salamander may be linked to oscillations observed in the OB. Considering that the OB oscillations modulate the responses in the primary olfactory cortices and PFC
(Kay et al., 2009), OE oscillations might be intermediated by the OB. In a previous study, the repetition attenuation observed in the $\mathrm{OB}$ is correlated with a reduction in the mitral-tufted cell firing rate during repetitive odor exposures, while the repetition attenuation observed in the $\mathrm{OE}$ is correlated with the olfactory receptor neuron firing rate, although the repetition attenuation in the OE is less than that in the OB (Philpot et al., 1997).

Despite these findings, the underlying function of the strengthened responses that were observed herein during exposure to deviant stimuli under anesthesia, in both the peripheral and central nervous systems, remains unclear. Clarifying this is especially important since olfactory sensory neurons in the $\mathrm{OE}$ are a bundle of independent sensors 
and are known to be unidirectional to the OB. Currently, there are two possible explanations for the strengthened responses. The first explanation is that the responses to standard stimuli are saturated while the responses to deviant stimuli are not saturated, and the second explanation is related to the perception-based modulation observed in the passive oddball response during unconscious situations (Silverstein et al., 2015). Animals anesthetized with urethane lose less sensory perception than animals anesthetized with other anesthetics do, depending on the pharmacological profile of the urethane, which has been described to consist of modest potentiation of gamma-aminobutyric acid-ergic and glycinergic transmission with modest depression of $\alpha$-amino3-hydroxy-5-methyl-4-isoxazolepropionic acid and $N$-methyl$\mathrm{D}$-aspartate receptors, which is similar to the function in awake animals (Hara and Harris, 2002; Neville and Haberly, 2003). This characteristic might contribute to the processing of sensory signals during an unconscious state. However, in both explanations, the mechanisms of the difference between the responses to standard and deviant stimuli in the $\mathrm{OE}$ are unknown, while the oddball response is known to influence higher-order regions (Silverstein et al., 2015). Further studies are needed to clarify the mechanism of oddball response on anesthetized animals.

In the present study, we selectively destroyed the mature olfactory neuroreceptors leaving progenitor cells intact with a treatment of $\mathrm{ZnSO}_{4}$ for test model (Cancalon, 1982) rather than creating lesions of the OE. The ultimate effect of $\mathrm{ZnSO}_{4}$ has been known to prohibit the axonal transportation to cells in the inner layers of the OB (McBride et al., 2003) and deactivate the glomerular layer of the OB (Cho et al., 2018). The destruction of $\mathrm{OE}$ has been reported in tetrodotoxin-treated model (Fletcher and Wilson, 2003), of which all types of cells were inhibited. Here, we observed similar effects in $\mathrm{ZnSO} 4$ treated mice suggesting that the olfactory receptor neurons play a key role in generating neural responses with respect to odors. So far, none of the chemical synapses have been known in signal transduction between olfactory receptor neurons, but the existence of gaseous second receptors or gap junctions or nitric oxide-mediated controls were evidenced as candidate for synchronizing neuronal firings (Breer et al., 1992; Levey et al., 1992; Ingi and Ronnett, 1995). Our observation of the significant reduction in the baseline delta power in $\mathrm{ZnSO}_{4}$-treated mice suggests the critical role of olfactory receptor neurons in genesis of delta oscillations.

Interestingly, we have observed that the baseline neuronal oscillations in the brain also changed as well. Recent reports suggest that mice olfactory deprived using $\mathrm{ZnSO}_{4}$ are more likely to develop cognitive and emotional impairments in chronic stress conditions (Chen et al., 2019) and have increased depressive and anxiolytic behaviors accompanied by a reduction of amygdalar corticotropin-releasing hormone (Ahn et al., 2018). To the best of our knowledge, the influence of the basal level dropping of the excitatory afferent sensory inputs on the resting-state activities of neurons or synaptic plasticity has not been reported. Nonetheless, some early sensory deprivation studies have reported an alteration in EEG alpha activities accompanied by hallucinatory experience (Hayashi et al., 1992), reflecting the possibility of critical influence of olfaction deprivation on the synaptic plasticity of neurons in the central nervous system.

\section{CONCLUSION}

In conclusion, our study using the oddball paradigm showed that impairments in the peripheral regions of the olfactory system may be revealed by measuring neural oscillations during passive odor stimulation. To the best of our knowledge, it is the first time that an olfactory oddball paradigm is used in relation with local field potential recording, and even under urethane anesthesia, a different oscillatory pattern was recorded for the deviant odor, independently of the odor used. Still, this study has limitations in acquiring dissociable signals from urethane or respiration to dissect the bottom-up signal processing of odor from the systemic alterations. Simultaneous monitoring of physiological parameters such as breathing or blood pressure as well as investigation of dose-dependency could be explored in future experiments. Lastly, these neural oscillation signatures may be utilized in establishing diagnostic guidelines for olfactory disorder patients.

\section{ETHICS STATEMENT}

All surgical and experimental procedures were followed by Korean Animal and Plant Quarantine Agency Publication No. 12512, partial amendment 2014, conforming to NIH guidelines (NIH Publication No. 86-23, revised 1985). All the procedures were approved by the Institutional Animal Care and Use Committee of the Korean Institute of Science and Technology (AP-2014L7002).

\section{AUTHOR CONTRIBUTIONS}

JC and J-HY conceptualized and designed the study. JK, JC, and J-HY wrote the manuscript. JK, J-GH, H-JC, and C-HK prepared the animals for surgery. JWK and $\mathrm{OB}$ built the experimental setup. JK and JWK acquired the data. JK, H-BH, and JC participated in data analysis and interpretation. All authors reviewed the manuscript.

\section{FUNDING}

This research was supported by the grant from the Korea Mouse Phenotyping Project (2016M3A9D5A01952414) of the Ministry of Science and Information and Communication Technology (ICT) through the National Research Foundation (NRF), by the Global Research Lab (GRL). Program of the NRF funded by Ministry of Science, Information, and Communication Technologies and Future Planning (2016K1A1A2910779), by the 
grant from the NRF of Korea funded by the Korea government (2017R1A2B3012659), and by the grant from the National Research Council of Science and Technology of Korea on the Project for the Development of Solutions for the Diagnosis, Treatment and Care System of Dementia (No. CRC-15-04-KIST).

\section{REFERENCES}

Ahn, S., Choi, M., Kim, H., Yang, E. J., Mahmood, U., and Kang, S. I. (2018). Transient anosmia induces depressive-like and anxiolytic-like behavior and reduces amygdalar corticotropin-releasing hormone in a $\mathrm{ZnSO} 4$-induced mouse model. Chem. Senses 43, 213-221. doi: 10.1093/chemse/bjy008

Baba, T., Kikuchi, A., Hirayama, K., Nishio, Y., Hosokai, Y., and Kanno, S. (2012). Severe olfactory dysfunction is predictive of dementia associated with Parkinson's disease: a 3-year longitudinal study. Mov. Disord. 27, S33-S34.

Beshel, J., Kopell, N., and Kay, L. M. (2007). Olfactory bulb gamma oscillations are enhanced with task demands. J. Neurosci. 27, 8358-8365. doi: 10.1523/ jneurosci.1199-07.2007

Boesveldt, S., Stam, C. J., Knol, D. L., Verbunt, J. P., and Berendse, H. W. (2009). Advanced time-series analysis of MEG data as a method to explore olfactory function in healthy controls and Parkinson's disease patients. Hum. Brain Mapp. 30, 3020-3030. doi: 10.1002/hbm.20726

Bramerson, A., Johansson, L., Ek, L., Nordin, S., and Bende, M. (2004). Prevalence of olfactory dysfunction: the skovde population-based study. Laryngoscope 114, 733-737. doi: 10.1097/00005537-200404000-00026

Breer, H., Klemm, T., and Boekhoff, I. (1992). Nitric-oxide mediated formation of cyclic-gmp in the olfactory system. Neuroreport 3, 1030-1032.

Cancalon, P. (1982). Degeneration and regeneration of olfactory cells induced by ZnSO4 and other chemicals. Tissue Cell 14, 717-733. doi: 10.1016/00408166(82)90061-1

Chen, Y., Zhou, H., An, Y., Jia, X., Sun, T., Guan, X., et al. (2019). Combined effects of olfactory dysfunction and chronic stress on anxietyand depressive- like behaviors in mice. Neurosci. Lett. 692, 143-149. doi: 10.1016/j.neulet.2018.11.010

Chi, V. N., Muller, C., Wolfenstetter, T., Yanovsky, Y., Draguhn, A., Tort, A. B. L., et al. (2016). Hippocampal respiration-driven rhythm distinct from theta oscillations in awake mice. J. Neurosci. 36, 162-177. doi: 10.1523/JNEUROSCI. 2848-15.2016

Cho, H. J., Lee, Y. H., Kim, B. R., Kim, H. K., Chung, H. J., and Park, S. C. (2018). Newly developed method for mouse olfactory behavior tests using an automatic video tracking system. Auris Nasus Larynx 45, 103-110. doi: 10.1016/j.anl.2017. 03.007

Deems, D. A., Doty, R. L., Settle, R. G., Moore-Gillon, V., Shaman, P., Mester, A. F., et al. (1991). Smell and taste disorders, a study of 750 patients from the University of Pennsylvania smell and taste center. Arch. Otolaryngol. Head Neck Surg. 117, 519-528. doi: 10.1001/archotol.1991.01870170065015

Devanand, D. P., Michaels-Marston, K. S., Liu, X., Pelton, G. H., Padilla, M., and Marder, K. (2000). Olfactory deficits in patients with mild cognitive impairment predict Alzheimer's disease at follow-up. Am. J. Psychiatry 157, 1399-1405. doi: 10.1176/appi.ajp.157.9.1399

Dorries, K. M., and Kauer, J. S. (2000). Relationships between odor-elicited oscillations in the salamander olfactory epithelium and olfactory bulb. J. Neurophysiol. 83, 754-765. doi: 10.1152/jn.2000.83.2.754

Doty, R. L. (2006). Olfactory dysfunction and its measurement in the clinic and workplace. Int. Arch. Occup. Environ. Health 79, 268-282. doi: 10.1007/s00420005-0055-6

Doty, R. L., Marcus, A., and Lee, W. W. (1996). Development of the 12-item cross-cultural smell identification test (CC-SIT). Laryngoscope 106, 353-356. doi: 10.1097/00005537-199603000-00021

Doty, R. L., Shaman, P., Applebaum, S. L., Giberson, R., Siksorski, L., and Rosenberg, L. (1984a). Smell identification ability: changes with age. Science 226, 1441-1443. doi: $10.1126 /$ science. 6505700

Doty, R. L., Shaman, P., Kimmelman, C. P., and Dann, M. S. (1984b). University of Pennsylvania smell identification test: a rapid quantitative olfactory function test for the clinic. Laryngoscope 94, 176-178. doi: 10.1288/00005537198402000-00004

\section{SUPPLEMENTARY MATERIAL}

The Supplementary Material for this article can be found online at: https://www.frontiersin.org/articles/10.3389/fnins. 2019.00478/full\#supplementary-material

Eskenazi, B., Cain, W. S., Novelly, R. A., and Mattson, R. (1986). Odor perception in temporal lobe epilepsy patients with and without temporal lobectomy. Neuropsychologia 24, 553-562. doi: 10.1016/0028-3932(86)90099-0

Estrem, S. A., and Renner, G. (1987). Disorders of smell and taste. Otolaryngol. Clin. North Am. 20, 133-147.

Fletcher, M. L., and Wilson, D. A. (2003). Olfactory bulb mitral-tufted cell plasticity: odorant-specific tuning reflects previous odorant exposure. J. Neurosci. 23, 6946-6955. doi: 10.1523/jneurosci.23-17-06946.2003

Fourcaud-Trocme, N., Courtiol, E., and Buonviso, N. (2014). Two distinct olfactory bulb sublaminar networks involved in gamma and beta oscillation generation: a CSD study in the anesthetized rat. Front. Neural Circ. 8:88. doi: 10.3389/fncir. 2014.00088

Frye, R. E., Schwartz, B. S., and Doty, R. L. (1990). Dose-related effects of cigarette smoking on olfactory function. JAMA 263, 1233-1236. doi: 10.1001/jama.263. 9.1233

Fukunaga, I., Herb, J. T., Kollo, M., Boyden, E. S., and Schaefer, A. T. (2014). Independent control of gamma and theta activity by distinct interneuron networks in the olfactory bulb. Nat. Neurosci. 17, 1208-1216. doi: 10.1038/nn. 3760

Gottfried, J. A., and Zald, D. H. (2005). On the scent of human olfactory orbitofrontal cortex: meta-analysis and comparison to non-human primates. Brain Res. Brain Res. Rev. 50, 287-304. doi: 10.1016/j.brainresrev.2005.08.004

Hamilton, K. A., and Kauer, J. S. (1989). Patterns of intracellular potentials in salamander mitral/tufted cells in response to odor stimulation. J. Neurophysiol. 62, 609-625. doi: 10.1152/jn.1989.62.3.609

Hara, K., and Harris, R. A. (2002). The anesthetic mechanism of urethane: the effects on rotransmitter-gated ion channels. Anesth. Analg. 94, 313-318. doi: 10.1213/00000539-200202000-00015

Hawkes, C. (2006). Olfaction in neurodegenerative disorder. $A d v$. Otorhinolaryngol. 63, 133-151. doi: 10.1159/000093759

Hawkes, C. H., Shephard, B. C., and Daniel, S. E. (1997). Olfactory dysfunction in Parkinson's disease. J. Neurol. Neurosurg. Psychiatry 62, 436-446.

Hayashi, M., Morikawa, T., and Hori, T. (1992). EEG alpha activity and hallucinatory experience during sensory deprivation. Percept. Mot. Skills 75, 403-412. doi: 10.2466/pms.1992.75.2.403

Hummel, T., Fliessbach, K., Abele, M., Okulla, T., Reden, J., and Reichmann, H. (2010). Olfactory FMRI in patients with Parkinson's disease. Front. Integr. Neurosci. 4:125. doi: 10.3389/fnint.2010.00125

Hummel, T., Sekinger, B., Wolf, S. R., Pauli, E., and Kobal, G. (1997). 'Sniffin' sticks': olfactory performance assessed by the combined testing of odor identification, odor discrimination and olfactory threshold. Chem. Senses 22, 39-52. doi: 10.1093/chemse/22.1.39

Ingi, T., and Ronnett, G. V. (1995). Direct demonstration of a physiological role for carbon monoxide in olfactory receptor neurons. J. Neurosci. 15, 8214-8222. doi: 10.1523/jneurosci.15-12-08214.1995

Ito, J., Roy, S., Liu, Y., Cao, Y., Fletcher, M., and Lu, L. (2014). Whisker barrel cortex delta oscillations and gamma power in the awake mouse are linked to respiration. Nat. Commun. 5:3572. doi: 10.1038/ncomms4572

Kay, L. M. (2014). Circuit oscillations in odor perception and memory. Prog. Brain Res. 208, 223-251. doi: 10.1016/B978-0-444-63350-7.00009-7

Kay, L. M., Beshel, J., Brea, J., Martin, C., Rojas-Libano, D., and Kopell, N. (2009). Olfactory oscillations: the what, how and what for. Trends Neurosci. 32, 207-214. doi: 10.1016/j.tins.2008.11.008

Kocsis, B., Pittman-Polletta, B. R., and Roy, A. (2018). Respiration-coupled rhythms in prefrontal cortex: beyond if, to when, how, and why. Brain Struct. Funct. 223, 11-16. doi: 10.1007/s00429-017-1587-8

Kollndorfer, K., Fischmeister, F. P., Kowalczyk, K., Hoche, E., Mueller, C. A., and Trattnig, S. (2015). Olfactory training induces changes in regional functional connectivity in patients with long-term smell loss. Neuroimage Clin. 9, 401-410. doi: 10.1016/j.nicl.2015.09.004 
Lapid, H., and Hummel, T. (2013). Recording odor-evoked response potentials at the human olfactory epithelium. Chem. Senses 38, 3-17. doi: 10.1093/chemse/ bjs073

Lepousez, G., Mouret, A., Loudes, C., Epelbaum, J., and Viollet, C. (2010). Somatostatin contributes to in vivo gamma oscillation modulation and odor discrimination in the olfactory bulb. J. Neurosci. 30, 870-875. doi: 10.1523/ JNEUROSCI.4958-09.2010

Levey, M. S., Cinelli, A. R., and Kauer, J. S. (1992). Intracellular injection of vital dyes into single cells in the salamander olfactory epithelium. Neurosci. Lett. 140, 265-269. doi: 10.1016/0304-3940(92)90117-p

Lieblich, J. M., Rogol, A. D., White, B. J., and Rosen, S. W. (1982). Syndrome of anosmia with hypogonadotropic hypogonadism (Kallmann syndrome): clinical and laboratory studies in 23 cases. Am. J. Med. 73, 506-519. doi: 10.1016/00029343(82)90329- 1

Lockmann, A. L. V., Laplagne, D. A., Leao, R. N., and Tort, A. B. L. (2016). A respiration-coupled rhythm in the rat hippocampus independent of theta and slow oscillations. J. Neurosci. 36, 5338-5352. doi: 10.1523/JNEUROSCI.345215.2016

Martin, C., and Ravel, N. (2014). Beta and gamma oscillatory activities associated with olfactory memory tasks: different rhythms for different functional networks? Front. Behav. Neurosci. 8:218. doi: 10.3389/fnbeh.2014.00218

McBride, K., Slotnick, B., and Margolis, F. L. (2003). Does intranasal application of zinc sulfate produce anosmia in the mouse? An olfactometric and anatomical study. Chem. Senses 28, 659-670. doi: 10.1093/chemse/bjg053

Meles, S. K., Vadasz, D., Renken, R. J., Sittig-Wiegand, E., Mayer, G., and Depboylu, C. (2017). FDG PET, dopamine transporter SPECT, and olfaction: combining biomarkers in REM sleep behavior disorder. Mov. Disord. 32, 1482-1486. doi: $10.1002 / \mathrm{mds} .27094$

Mori, K., Manabe, H., Narikiyo, K., and Onisawa, N. (2013). Olfactory consciousness and gamma oscillation couplings across the olfactory bulb, olfactory cortex, and orbitofrontal cortex. Front. Psychol. 4:743. doi: 10.3389/ fpsyg.2013.00743

Muller, A., Reichmann, H., Livermore, A., and Hummel, T. (2002). Olfactory function in idiopathic Parkinson's disease (IPD): results from cross-sectional studies in IPD patients and long-term follow-up of de-novo IPD patients. J. Neural Transm. 109, 805-811. doi: 10.1007/s007020200067

Murphy, C., Schubert, C. R., Cruickshanks, K. J., Klein, B. E., Klein, R., and Nondahl, D. M. (2002). Prevalence of olfactory impairment in older adults. JAMA 288, 2307-2312.

Neville, K. R., and Haberly, L. B. (2003). Beta and gamma oscillations in the olfactory system of the urethane-anesthetized rat. J. Neurophysiol. 90, 39213930. doi: 10.1152/jn.00475.2003

Okano, M., and Takagi, S. F. (1974). Secretion and electrogenesis of the supporting cell in the olfactory epithelium. J. Physiol. 242, 353-370. doi: 10.1113/jphysiol. 1974.sp010711

Parker, J. M., Chang, Q., and Caprio, J. (2000). Citrate enhances olfactory receptor responses and triggers oscillatory receptor activity in the channel catfish. J. Neurophysiol. 83, 2676-2681. doi: 10.1152/jn.2000.83.5.2676

Paxinos, G., Franklin, K. B. J., and Franklin, K. B. J. (2001). The Mouse Brain in Stereotaxic Coordinates. San Diego, CA: Academic Press.

Philpot, B. D., Foster, T. C., and Brunjes, P. C. (1997). Mitral/tufted cell activity is attenuated and becomes uncoupled from respiration following naris closure. J. Neurobiol. 33, 374-386. doi: 10.1002/(sici)1097-4695(199710)33:4<374::aidneu3>3.0.co;2-7

Reichert, J. L., Postma, E. M., Smeets, P. A. M., Boek, W. M., de Graaf, K., and Schopf, V. (2018). Severity of olfactory deficits is reflected in functional brain networks-An fMRI study. Hum. Brain Mapp. 39, 3166-3177. doi: 10.1002/hbm. 24067
Schriever, V. A., Han, P., Weise, S., Hosel, F., Pellegrino, R., and Hummel, T. (2017). Time frequency analysis of olfactory induced EEG-power change. PLoS One 12:e0185596. doi: 10.1371/journal.pone.0185596

Schubert, C. R., Cruickshanks, K. J., Fischer, M. E., Huang, G. H., Klein, B. E., and Klein, R. (2012). Olfactory impairment in an adult population: the beaver dam offspring study. Chem. Senses 37, 325-334. doi: 10.1093/chemse/bjr102

Scott, J. W., and Scott-Johnson, P. E. (2002). The electroolfactogram: a review of its history and uses. Microsc. Res. Tech. 58, 152-160.

Shibuya, T. (1964). Dissociation of olfactory neural response and mucosal potential. Science 143, 1338-1339. doi: 10.1126/science.143.3612.1338

Silverstein, B. H., Snodgrass, M., Shevrin, H., and Kushwaha, R. (2015). P3b, consciousness, and complex unconscious processing. Cortex 73, 216-227. doi: 10.1016/j.cortex.2015.09.004

Suzuki, M., Saito, K., Min, W. P., Vladau, C., Toida, K., Itoh, H., et al. (2007). Identification of viruses in patients with postviral olfactory dysfunction. Laryngoscope 117, 272-277. doi: 10.1097/01.mlg.0000249922.37381.1e

Suzuki, N., Takahata, M., Shoji, T., and Suzuki, Y. (2004). Characterization of electro-olfactogram oscillations and their computational reconstruction. Chem. Senses 29, 411-424. doi: 10.1093/chemse/bjh042

Thomas-Danguin, T., Rouby, C., Sicard, G., Vigouroux, M., Farget, V., and Johanson, A. (2003). Dumont, development of the ETOC: a European test of olfactory capabilities. Rhinology 41, 142-151.

Turetsky, B. I., Moberg, P. J., Yousem, D. M., Doty, R. L., Arnold, S. E., and Gur, R. E. (2000). Reduced olfactory bulb volume in patients with schizophrenia. Am. J. Psychiatry 157, 828-830. doi: 10.1176/appi.ajp.157.5.828

Vanderwolf, C. H. (2000). What is the significance of gamma wave activity in the pyriform cortex. Brain Res. 877, 125-133. doi: 10.1016/s0006-8993(00) 02568-3

Vennemann, M. M., Hummel, T., and Berger, K. (2008). The association between smoking and smell and taste impairment in the general population. J. Neurol. 255, 1121-1126. doi: 10.1007/s00415-008-0807-9

Versace, V., Langthaler, P. B., Sebastianelli, L., Holler, Y., Brigo, F., and Orioli, A. (2017). Impaired cholinergic transmission in patients with Parkinson's disease and olfactory dysfunction. J. Neurol. Sci. 377, 55-61. doi: 10.1016/j.jns.2017.03.049

Wang, J., Eslinger, P. J., Doty, R. L., Zimmerman, E. K., Grunfeld, R., and Sun, X. (2010). Olfactory deficit detected by fMRI in early Alzheimer's disease. Brain Res. 1357, 184-194. doi: 10.1016/j.brainres.2010.08.018

Wang, J., Eslinger, P. J., Smith, M. B., and Yang, Q. X. (2005). Functional magnetic resonance imaging study of human olfaction and normal aging. J. Gerontol. A Biol. Sci. Med. Sci. 60, 510-514. doi: 10.1093/gerona/60.4.510

Yanovsky, Y., Ciatipis, M., Draguhn, A., Tort, A. B. L., and Brankack, J. (2014). Slow oscillations in the mouse hippocampus entrained by nasal respiration. J. Neurosci. 34, 5949-5964. doi: 10.1523/JNEUROSCI.5287-13.2014

Zusho, H. (1982). Posttraumatic anosmia. Arch. Otolaryngol. 108, 90-92. doi: 10.1001/archotol.1982.00790500026006

Conflict of Interest Statement: The authors declare that the research was conducted in the absence of any commercial or financial relationships that could be construed as a potential conflict of interest.

Copyright (c) 2019 Kum, Kim, Braubach, Ha, Cho, Kim, Han, Choi and Yoon. This is an open-access article distributed under the terms of the Creative Commons Attribution License (CC BY). The use, distribution or reproduction in other forums is permitted, provided the original author(s) and the copyright owner(s) are credited and that the original publication in this journal is cited, in accordance with accepted academic practice. No use, distribution or reproduction is permitted which does not comply with these terms. 